\title{
Introducing a socio-technical perspective on business processes into Enterprise Interoperability Frameworks
}

\author{
Charles Crick and Eng K. Chew \\ Faculty of Engineering and Information Technology, University of Technology, Sydney \\ charlescrick@computer.org, eng.chew@uts.edu.au
}

\begin{abstract}
This paper looks at enterprise interoperability (EI), specifically process-level interoperability, and suggests that the inherent non-determinacy of human-centred business processes introduces another ingredient into the EI puzzle that has thus far been understated in EIF ontologies. A conceptualisation of business process based on socio-technical concepts is presented. It is argued that this provides a better way to accommodate human agency factors, and under the influence of these factors, how business processes inevitably evolve over time, potentially affecting their interoperability. We suggest the extant body of knowledge on the theory of dy namic cap abilities is relevant to understanding how organisations can control this potentially undirected process evolution and thereby sustain interoperability. Some initial observations are made concerning how this new ontological element could be accommodated into existing EIFs. The paper aims to stimulate discussion in this area and make a contribution to the EI body of knowledge.
\end{abstract}

Keywords: Socio-technical systems, business process ontology, technology affordance, enterprise interoperability, dy namic capabilities

\section{Introduction}

Generally, an Enterprise Interoperability Framework (EIF) is a way of structuring knowledge in the enterprise interoperability (EI) domain, such that we may reason about problems such as barriers to interoperability and understand possible solutions. As pointed out by Guédria et al. [1], in their review of the state of research in this area, there are several EIFs in existence, well known examples including the ATHENA (Advanced Technologies for interoperability Heterogeneous Enterprise Networks and Applications) Interoperability Framework [2]; the European Interoperability Framework [3]; and the FEI [4, 5], the latter is also a published ISO standard. These frame works have their foundations in the discipline of Enterprise Architecture [6], where the enterprise is modeled across a number of domains (such as business, data, technology), at a number of levels of abstraction (e.g. conceptual to physical) and generally in terms of determin istic artefacts such as business processes, data entities, applications and so forth. We use the term deterministic in the sense that the artefacts are well defined objects that can be designed, analysed and modeled etc. In 
this paradigm, interoperability is characterised in terms of relationships between these objects, for example, communicating IT applications or business processes that need to interoperate in order to deliver an outcome. This representation also facilitates fairly straightforward quantification of interoperability, such as with the i-Score method [7], since the relationships and artefacts can be reduced to deterministic graph structures that can be analysed with mature algorithms.

In this paper we suggest the need for an additional ingredient in th is EI picture, one that is bound up in the intrinsic non-determinacy of the human actors that take part in the activities of the enterprise, and which must therefore, we believe, be taken into account when we want to talk about behavioral aspects of EI. Naudet et al. [8] hint at this issue in their characterisation of organisational interoperability concerns, but in our view fall short of catering for the implicit dynamics involved.

Our response to this is sue is to include a socio-technical dimension in the conceptualisation of business process, informing this view, in particular, with the theory of organisational routines [9] and technology affordances [10, 11], drawn from management sciences, both of which centre around the role of the human agency. We argue that these concepts introduce an adaptive element into the idea of interoperating processes such that a barrier in, for example, the technology layer may be simply "worked around" by improvisation. Our main point is that this occurs as part of business-as-usual, rather than through any intentional intervention. As argued by Schreyögg and Kliesch-Eberl [12], this type of organisational learning places a requirement on the part of management to exercise a second-order activity that monitors business-as-usual to detect and make corrections. Such second-order activities, or dynamic capabilities [13], are crucial mechanis ms by which organisations maintain their alignment with the environment, or their evolutionary fitness [14], which includes their ability to maintain interoperability.

The remainder of this paper is structured as follows. First we set out our conceptual model of business process and provide its theoretical underpinnings. We then go on to discuss how this impacts the EI ontological model $[4,8]$.

\section{Conceptualising Business Process as a Socio-Technical Object}

\subsection{Ontological Perspectives}

The business process (BP) is a familiar Information Systems (IS) concept. Weske's definition is a typical definition used in the IS literature: "A business process consists of a set of activities that are performed in coordination in an organisational and technical environment. These activities jointly realize a business goal. Each business process is enacted by a single organisation, but it may interact with business processes performed by other organisations." $[15$ p.6]. The idea of BP as determin istic, executable entities is central to this conceptualisation and has led to the rise of Business Process Management (BPM) and associated technologies as a popular IS discipline [16]. The conventional modeling and analysis of the interoperability of business processes also relies on this view. In some cases, of course, business processes are fully automated and operate without any human participation, and are in that sense deter- 
ministic. However, we argue, when there is human agency involved in the processes, this is an overly simplistic perspective, and any ontology that underpins a model of interoperability needs a way of teasing apart the deterministic and the nondeterministic elements.

Attempts have been made to admit other ontological perspectives into the business process concept, such as BP based on complex systems theory [e.g. 17, 18], for example. The importance of context when considering the instantiation of a BP has been recognised, both in terms of how it contributes to flexibility [19] and how it can be modeled [20]. There are several dimensions that provide context, such as, for example, the circumstances of the organisational environment providing the backdrop for the particular BP instance, or substitution of different participant roles when the process is actually executed. The BP literature is mostly silent, however, on the context ualisation attributable to the human part ic ipants, or other words, how the hu man participants construct the business process instance, in the act of practicing it, within a given situation.

The organisational routine concept [9], which has been developed in the management sciences largely outside of IS, provides a relevant insight into the role of human agency. This theory distinguishes a duality of "ostensive" and "performative" facets the former representing the idealised, codified representation of the routine and the latter the routine-in-use, or what actually happens in practice. The implication here is that the routine may be performed differently each time it is repeated even if the ostensive aspect remains the same. We argue the distinction between the ostensive and performative aspects also has relevance to how business process should be conceptualised. It suggests that there has been a missing ingredient in the traditional IS orthodoxy when it comes to business processes [e.g. 15, 16, 21]. That is, we cannot treat a business process merely as an artefact that can be deterministically executed. Instead we argue that the non-determinacy of human agency must be factored in: the processas-designed is different from the process-as-performed. Human factors such as motivation, skills, tacit knowledge and experience, intrinsically mean the process may not deliver what was "intended".

\subsection{The Role of Technology}

The idea of the performative routine is taken a step further into the socio-technical realm by the concept of the technology affordance [10, 11, 22, 23]. An affordance represents the perception of what can be done with an item of technology by a user with a particular goal - i.e. the affordance is the potentiality for action of a technology feature, not necessarily how the feature was designed. Thus the way technology is used (by a human user) in the business process is a function of the potentiality of the technology (for action) as perceived by the users, rather than just a set of pre-designed technology features. 


\subsection{Conceptual Model}

In this section we explain our conceptualisation of business process that has been informed by the theoretical foundations discussed above. The purpose here is to understand how the human-centred factors give rise to intrinsically adaptive behavior whereby the business processes can evolve away from any a priori design, with ramifications for process-based enterprise interoperability.

We start with the intra-organisational view depicted in Fig. 1. This model situates the business process concept within the enterprise using the idea of organisational capability $[24,25]$ to model the outcome achieved by the business process. The numbered labels on the diagram refer to key component relationships in the model that are explained below.

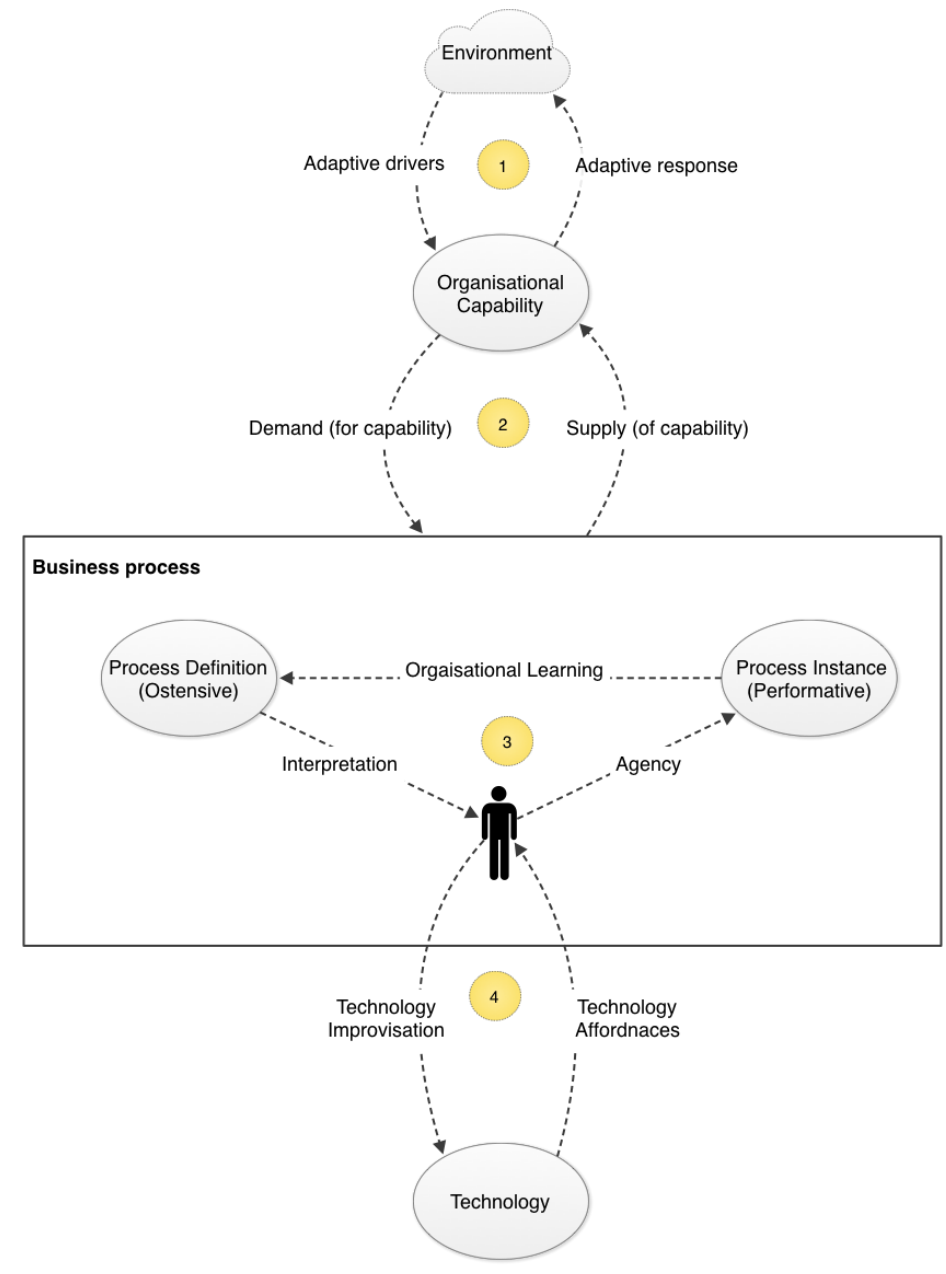

Fig. 1. - Conceptual Model of Business Process 
1. Adaptive response. This relationship represents the requirement for "evolutionary fitness" [14] on the part of the organisation's capabilities. The environment exerts pressure for the organisation to adapt its portfolio of organisational capabilities. The organis ation responds to meet this selective pressure by detecting the need to change and then redesigning or redeploying its resources, including business processes, to achieve the necessary outcome. In a commercial environment, a capability such as "manufacture cars" has an evolutionary fitness that is a function of the market demand and the competitors' products. For a non-commercial business, the adaptive imperative may come from a regulatory change, for example.

2. Demand/Supply Alignment. This is the central organisational alignment relationship whereby the external demand pressure for a given capability is met (or not) by the supply side: or in otherwords the ability of the organisation's business processes to deliver such a capability.

3. Process Evolution. The ostensive business process is interpreted every time it is practiced by the human actor. The loop back from the performative to the ostensive means that the ostensive is not a static representation of some $a$ prioridesign: instead it is a definition that moves in line with what is learned from practice. "Learned" is used in a wide sense here: it not only refers to an intentional activity but also it is the necessary by-product of performativeostensive relationship. So in this latter sense, it is inevitable that the practice will induce a drift away from the process-as-designed. This is consistent with the Feldman and Pentland's original characterisation of routines [26] and their more recent work on modeling this experiential learning [27]. This form of organisational learning confers a bottom-up adaptive capacity whereby the business processes can evolve to meet a new organisational capability need and thus enable or maintain evolutionary fitness.

4. Technology Imbrication. This represents the socio-technical relationship whereby the features available in the technology are interpreted by the user into a set of affordances [10]. These affordances are the product of the user's particular goals, experience and skills providing a unique context for how the technology features (as designed) are perceived as part of the business process. In line with Leonardi [11], the value of the technology only emerges when there is imbrication with human agency, or in other words, there is an interdependent relationship between the two. The other side of the imbrications relationship is that technology is improvised, or worked-around, when the affordance presented by the technology is inadequate for the task at hand. These improvisations, in turn, give rise to more affordances for other actors. 


\subsection{Inter-Organisational View}

If we look at a process-level interoperability, as is described in the FEI $[4,5]$, a consequence of this is illustrated in Fig. 2. In the top part of the diagram (A) we have interoperating processes between the two enterprises. After some elapsed time we get a situation where the interoperability may be threatened, for example, by a constraint that is operating in the technology layer. The process, due to the human agency, adapts so as to maintain the interoperability, as shown in Fig. 2 (B). People learn to workaround constraints and their improvised solutions become "business as usual" over time. Common instances of this phenomenon are where spreadsheets are used to augment data not (or perceived not to be) catered for in corporate IT systems. These evolve to become de-facto systems of record rather than temporary fixes. In an order to cash process between a customer and supplier, the process is often sustained by the inter-relationships of human intermediaries, such as when the procurement officer in one company knows who to call in the supplier company to get prompt attention.

A corollary of the unilateral "evolutionary drift" of the business processes depicted in Fig. 2, is that interoperation may stop working rather than continue to be maintained.

The important point is that in both cases adaptation has occurred through the normal interpret-agency-learn cycle, labeled (3) in Fig. 1, rather than through any intentional process redesign.

\section{(A) time $=0$}

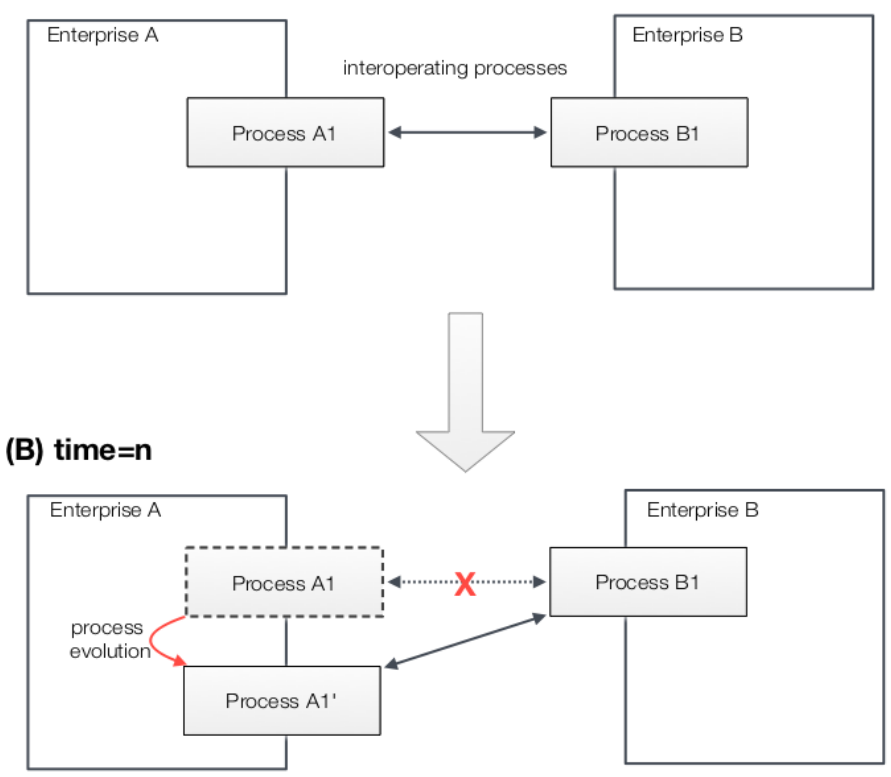

Fig. 2. - Interoperability and process evolution 


\section{Insights for Enterprise Interoperability Frameworks}

The conceptual model we have presented above contains two aspects that we argue need to be addressed in the discussion relating to enterprise interoperability, and thence in the formulation of EIFs that seek to describe and structure knowledge about this domain. The first is that there is an inherently non-deterministic component in the concept of business process that is a function of the agency of human actors. The second is that in the course of a (human-centered) business process being practiced, what the enterprise understands the process to be, or its ostensive component, will inevitably drift away from any a priori version that may have been designed. We suggest that if our objective in formulating EIFs is to provide a way to structure and thence gain insight into the interoperability problem domain, we need to understand these effects and incorporate them into the EIF ontology.

So, how might we proceed with this objective of accommodating the human agency effects into an EIF ontology? If we take the Chen and Daclin (then nascent) ontology for FEI [4], we can see that (business) process is represented as a type of concern, which forms one of the dimensions in their EI model of the Problem Space, the other being barrier. The FEI then addresses interoperability as the solution to a problem in terms of how a concern/barrier is mapped to an approach in the Solution Space. Thus, in FEI parlance, processes across two enterprises will interoperate if all the barriers are solved. The focus is not so much conditions for EI, then, but conditions for where EI will fail. Clearly this model, as does Naudet et al. [8], relates to a situation at a point in time, be that a priori, when a potential EI problem can be designed for; or $a$ posteriori, when an interoperability problem actually surfaces. What is needed to accommodate the evolutionary process we describe, is a more dynamic approach. The relationship between problem and solution is more complex than these existing models allow for. The process whereby an interoperability problem is "headed off" before it actually happens by an adaptation of the business processes involved, is an example of this type of dynamics. The concept of dynamic capability [13, 28], from the management sciences literature, provides a theoretical basis for further understanding this phenomenon. It suggests $[12,29]$ the existence of a second-order cybernetic capacity that performs a monitor and alignment function that operates on the first-order business process system described. This function would act to maintain the alignment of the interoperating business processes to the required outcome, characterised in terms of the required organisational capability (e.g a successful order to cash process between customer and supplier). Without this higher order function, there is no guarantee where the evolutionary process drift will lead.

\section{Conclusion and Perspectives}

In this paper, we have introduced a new theoretical element into the EI discourse, namely duality of ostensive and performative business processes that emerges from human agency. In this we have sought to stimulate discussion on how well studied organisational phenomena, drawn from management sciences and organisational sci- 
ence, factor into the traditionally technical realm of EI and EIFs. So me questions that arise have been touched on: how does the intrinsic adaptive nature of human-centered business processes play into EI and EIFs? When is EI "broken" at the business process level, given there is some capacity within the organisation to "fix" problems without any special intervention? Are these process-level workarounds compensating for inadequate technology? What are the implications for enterprise managers whose business model relies on process -level EI - e.g. with partner organisations - to deliver capability to their end-customers? In particular how can we apply the extant body of knowledge from the management sciences, including the theory of dynamic capabilities, to this area? We hope to investigate these issues further and to add to the burgeoning body of knowledge in this important field.

\section{References.}

1. Guédria, W., Naudet, Y., Chen, D.: Maturity model for enterprise interoperability. Enterp. Inf. Sy st. 1-28 (2013).

2. Ruggaber, R.: ATHENA - Advanced Technologies for Interoperability of Heterogeneous Enterprise Networks and their Applications. Interoperability Enterp. Softw. Appl. 459-462 (2006).

3. EIF: European Interoperability Framework, White Paper. European Commission, Brussels (2004).

4. Chen, D., Daclin, N.: Framework for enterprise interoperability. Proc. IFAC Work. EI2N. 77-88 (2006).

5. Chen, D.: Enterprise Interoperability. EMOI-INTEROP (2006).

6. Chen, D., Doumeingts, G., Vernadat, F.: Architectures for enterprise integration and interoperability: Past, present and future. Comput. Ind. 59, 647-659 (2008).

7. Ford, T., Colombi, J., Graham, S., Jacques, D.: The Interoperability Score. Proceeding of the 5th Annual Conference on Systems Engineering Research., Hoboken, NJ (2007).

8. Naudet, Y., Latour, T., Guedria, W., Chen, D.: Towards a sy stemic formalisation of interoperability. Comput. Ind. 61, 176-185 (2010).

9. Pentland, B., Feldman, M.: Organizational routines as a unit of analy sis. Ind. Corp. Chang. 14, 793-815 (2005).

10. Zammuto, R.F., Griffith, T.L., Majchrzak, A., Dougherty, D.J., Faraj, S.: Information technology and the changing fabric of organization. Organ. Sci. 18, 749-762 (2007).

11. Leonardi, P.: When flexible routines meet flexible technologies: Affordance, constraint, and the imbrication of human and material agencies. MIS Q. 35, 147-167 (2011).

12. Schrey ogg, G., Kliesch-Eberl, M.: How dynamic can organizational capabilities be? Towards a dual-process model of capability dy namization. Strateg. Manag. J. 28, 913933 (2007).

13. Teece, D., Pisano, G., Shuen, A.: Dynamic capabilities and strategic management. Strateg. Manag. J. 18, 509-533 (1997).

14. Helfat, C., Finkelstein, S., Mitchell, W., Peteraf, M., Singh, H., Teece, D., Winter, S.: Dy namic capabilities: understanding strategic change in organizations. Blackwell, Oxford (2007).

15. Weske, M.: Business Process Management - Concepts Languages Architectures. Springer, New York (2012).

16. Van Der Aalst, W., Hofstede, A., Weske, M.: Business process management: A survey. Business Process Management. pp. 1-12. Springer, Berlin Heidelberg (2003). 
17. Melão, N., Pidd, M.: A conceptual framework for understanding business processes and business process modelling. Inf. Syst. J. 10, 105-129 (2000).

18. Vidgen, R., Wang, X.: From business process management to business process ecosystem. J. Inf. Technol. 21, 262-271 (2006).

19. Rosemann, M., Recker, J., Flender, C.: Contextualisation of business processes . Int. J. Bus. Process Integr. Manag. 3, 47-60 (2008).

20. Saidani, O., Nurcan, S.: Towards context aware business process modelling. Proceedings of the 8th Workshop on Business Process Modeling, Development, and Support (BPMDS 2007) (2007).

21. Hammer, M., Champy, J.: Reengineering the Corporation: Manifesto for Business Revolution. Harper Business (1993).

22. Majchrzak, A., Markus, M.: Technology affordances and constraints. In: Kessler, E. (ed.) Encyclopedia of Management Theory. Sage (2012).

23. Yoo, Y., Boland, R.: Organizing for innovation in the digitized world. Organ. Sci. 23, 1398-1408 (2012).

24. Helfat, C.: The evolution of firm capabilities. Strateg. Manag. J. 21, 955-959 (2000).

25. Helfat, C., Winter, S.: Untangling dy namic and operational capabilities: strategy for the (n)ever-changing world. Strateg. Manag. J. 32, 1243-1250 (2011).

26. Feldman, M., Pentland, B.: Reconceptualizing Organizational Routines as a Source of Flexibility and Change. Adm. Sci. Q. 48, 94-118 (2003).

27. Pentland, B., Feldman, M., Becker, M., Liu, P.: Dynamics of organizational routines: A generative model. J. Manag. Stud. 49, 1484-1508 (2012).

28. Teece, D., Pisano, G.: The dy namic capabilities of firms: an introduction. Ind. Corp. Chang. 3, 537-556 (1994).

29. Weerdt, N.P. Van Der, Volberda, H., Verwaal, E., Stienstra, M.: Organizing for Flexibility: Addressing Dynamic Capabilities and Organization Design. In: Bøllingtoft, A., Donaldson, L., Huber, G.P., Håkonsson, D.D., and Snow, C.C. (eds.) Collaborative Communities of Firms: Purpose, Process, and Design. pp. 105-125. Springer New York, New York, NY (2012). 